\title{
PERIPHERAL ENTHESOPATHY: AN OSTEOLOGICAL STUDY
}

\section{S. Behera ${ }^{1}$, S. Singh ${ }^{2}$, M. Sar *3.}

${ }^{1,2}$ Assistant Professor, Department of Anatomy, V.S.S.Institute of Medical Sciences \& Research, Burla, Sambalpur, Odisha, India.

${ }^{* 3}$ Associate Professor, Department of Anatomy, V.S.S.Institute of Medical Sciences \& Research, Burla, Sambalpur, Odisha, India.

\section{ABSTRACT}

Introduction: Enthesis is the site of attachment of tendon or ligament to the bone. Enthesitis is characterized by erosive, inflammatory lesions that may undergo ossification. Ossified entheses are commonly described as enthesophytes. Enthesitis is a common clinical finding in spondyloarthropathies (SpA). Diffuse idiopathic skeletal hyperostosis (DISH) is another condition which is characterized by ossification of entheses, Entheseal ossifications are usually observed during our bone demonstrations to Medical students.

Objective: To describe the sites and frequency of ossification of entheses in the appendicular skeleton.

Materials andMethods: This is an observational study conducted by examining matured and intact bones of upper and lower limbs procured from the osteology section of the Department of Anatomy, VSS Institute of medical sciences and research to find out if there is any ossification of ligaments or tendons at their attachment sites.

Results: Entheseal ossifications were more common in bones of the lower limb in comparison to that of the upper limb. Distal parts of the lower limb were more involved by entheseal ossification compared to the proximal parts. Ligamentum patelli (33\%), achillis tendon(32\%) \& plantar aponeurosis (27.5\%) were the most common structures ossified and presented as bony spurs at their attachment sites to the calcaneum and tibial tuberosity. In the upper limb, most of the entheseal ossification sites were around elbow joint, like medial epicondyle, lateral epicondyle, radial tuberosity, olecranon process, and articular margin of elbow joint.

Conclusion: In addition to the usual sites of entheseal ossification described in previous imaging studies, many new sites of involvement were detected on gross examination of bones. This study can guide the clinicians and radiologists to focus on these unusual sites to correlate with their findings.

KEYWORDS: Enthesis, Enthesophytes, Spondyloarthropathy, DISH, Ossification, Spur.

Corresponding Author: Dr. Mamata Sar, Associate Professor, Department of Anatomy, V.S.S.Institute of Medical Sciences\& Research, Burla, Sambalpur, Odisha, India. E-Mail: mamatasar@gmail.com

Access this Article online

Quick Response code

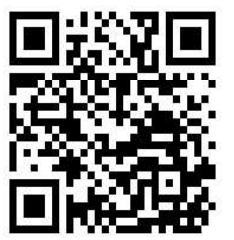

DOI: $10.16965 /$ ijar.2020.178

Journal Information

\section{International Journal of Anatomy and Research}

RG Journal ISSN (E) 2321-4287 | ISSN (P) 2321-8967

Impact: 0.21* https://www.ijmhr.org/ijar.htm

DOI-Prefix: https://dx.doi.org/10.16965/ijar

$(c c)$ ET-Mo-Bh

Article Information

Received: 24 Jun 2020

Peer Review: 24 Jun 2020

Revised: None
Accepted: $28 \mathrm{Jul} 2020$

Published (O): 10 Aug 2020

Published (P): 10 Aug 2020

\section{INTRODUCTION}

Enthesis is the site of attachment of tendon or ligament to the bone. There are two types of the enthesis, fibrous and fibrocartilaginous. Fibrous entheses are usually found at the site of attachment of massive muscle bodies to long bones which are mostly large areas of the diaphyses or metaphyses thus dissipating stress from tendons over bone tissue. Fibrocartilaginous entheses have more sophisticated architecture, attached to epiphyses, often in the vicinity of synovial joints. In addition to the dispersion of contractile force, they allow precise limb movement about the joints. Most of 
the entheses in the body are fibrocartilaginous. These may incorporate uncalcified as well as calcified fibrocartilage, fat pads, bursae, and synovium in addition to the tendon, composed of dense fibrous connective tissue and adjacent bone [1,2].

Due to their location at the interface of ligaments and bones, entheses are more prone to mechanical forces. Both mechanical and inflammatory factors can trigger enthesitis $[3,4]$.

Inflammation of enthesis or enthesitis is a common clinical finding in spondyloarthr opathies (SpA). These are a group of chronic inflammatory disorders characterized by asymmetrical peripheral arthritis predominantly of lower limbs and axial skeletal inflammation. Enthesitis is characterized by erosive, inflammatory lesions that may undergo ossification $[5,6]$.

Ossified entheses are commonly described as enthesophytes.Diffuse idiopathic skeletal hyperostosis (DISH) is another condition that is characterized by ossification of entheses, especially in the axial skeleton but also in peripheral entheses [7]. DISH is a systemic, relatively common condition, with an average prevalence of approximately $10 \%$ in people $>50$ years of age $[7,9]$.

Most commonly entheseal ossifications are localized around the spine. Peripheral enthesopathic abnormalities are more frequently reported from the lower limb $[8,9]$.

Capsules of synovial joints, ligamentum patelli, tendoachilis, and plantar fascia are described to be involved frequently[10]. These are detected by X-ray, Ultrasound, CT scan, or MRI in patients suffering from various types of spondyloarthropathies and DISH.

Entheseal ossifications were usually observed during our bone demonstrations to Medical students. In addition to the commonly described areas, ossification of entheses were observed by us in some unusual structures like interosseous membrane, intermuscular septa, transverse scapular ligament, costoclavicular ligament, etc. Though upper limb enthesophytes are rarely reported, those were also observed in many parts of upper limb bones. The bones we studied for entheseal ossifications were of an unknown source, so the etiology of entheseal ossifications were not clear. Therefore the present study was conducted to describe only the sites and frequency of bony proliferation at entheseal sites in the appendicular skeleton. As only imaging studies are available on this topic, an osteological study on dry bones may add some useful information to the existing knowledge of enthesopathy.

\section{MATERIALS AND METHODS}

All the intact matured bones of upper and lower limbs preserved in the osteology section of the Department of Anatomy, VSS Institute of medical sciences, and research were included in our study. This is an observational study conducted to find out the sites of attachments of ligaments and tendons where they have been ossified. We also calculated the percentage of involvement of these structures to describe their frequency.

\section{RESULTS}

Among lower limb bones, enthesophytes were found in all long bones including other bones like patella and calcaneum. Out of 152 femurs, ossification was found in 20 entheseal sites highest being the capsular ligament of the knee joint (5.2\%) at the articular margin of condyles. $33 \%$ of ligamentum patellae at tibial tuberosity showed entheseal ossification among 77 tibias. Single fibula out of 58 had enthesophytes at malleolar fossa due to posterior talofibular ligament ossification. Patella showed enthesophytes at its base and apex due to the ossification of quadriceps tendon (12.5\%) and ligamentum patellae (2.7\%). Among short bones, only calcaneum had bony spurs at the attachment sites of tendoachillis (32\%) and plantar aponeurosis (27.5\%) [Table1]. Among upper limb bones, suprascapular ligaments (6\%), costoclavicular ligaments(13.5\%), capsular ligament of the shoulder (4\%) and elbow joint (1\%), common flexor (2\%) and extensor tendons (1\%) were found to be ossified at their attachment sites. Ossification of the interosseous membrane (11\%) was observed at its radial attachment. In radius and ulna tendons of biceps and triceps were ossified at their sites of insertion respectively [Table 2]. 


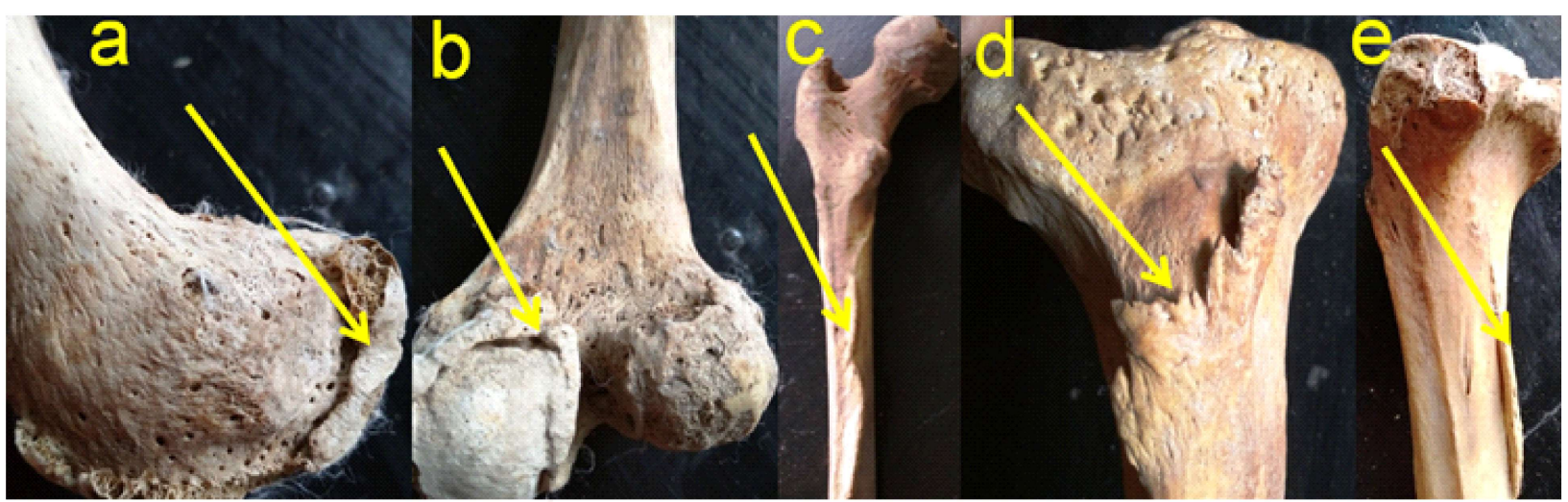

Fig. 1: Enthesophytes at Articular margin of condyles of femur (a,b), Spiral line and medial lip of linea aspera(c), Tibial tuberosity (d), Soleal line(e).

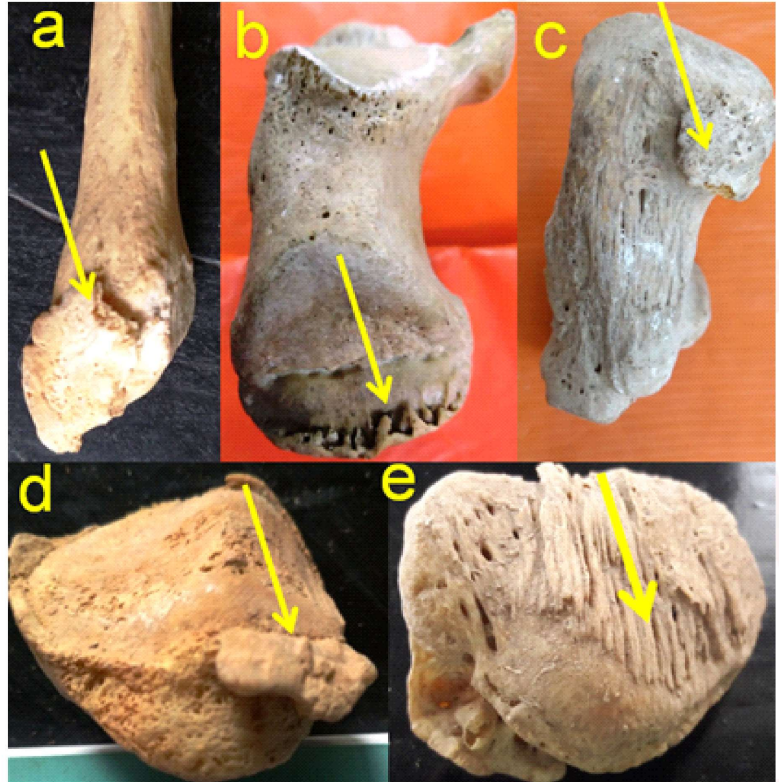

Fig. 2: Enthesophytes at Malleolar fossa of fibula (a), Proximal surface of calcaneum(b), Medial process on the plantar surface of calcaneum (c), Apex of patella(d), base of patella (e).

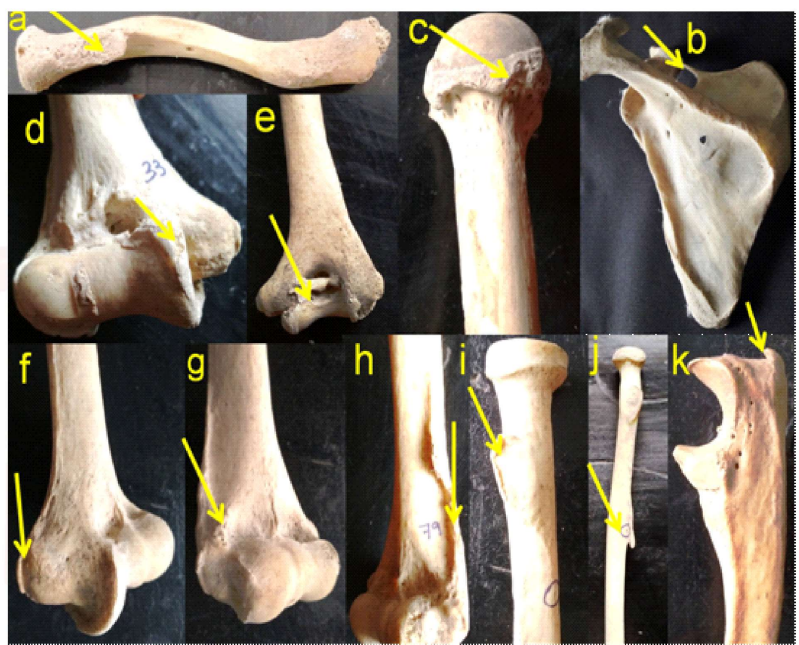

Fig. 3: Enthesophytes at Inferior surface of the medial end of the clavicle(a), Suprascapular notch(b), Anatomical neck of humerus (c), Articular margin of lower end of the humerus(d, e), Lateral supracondylar ridge of the humerus(f), medial epicondyle of the humerus(g), Lateral epicondyle of the humerus(h), Radial tuberosity of radius (i), Interosseous border of the radius(j), Olecranon process of the $u l n a(k)$.

Table 1: Ossification of enthesis in lower limb bones.

\begin{tabular}{|c|c|c|c|c|c|}
\hline $\begin{array}{l}\text { Name of the } \\
\text { bone }\end{array}$ & $\begin{array}{l}\text { Number of } \\
\text { bones }\end{array}$ & Enthesis involved & $\begin{array}{l}\text { Sites of attachment to the } \\
\text { bone }\end{array}$ & $\begin{array}{l}\text { No. of ossified } \\
\text { enthesis }\end{array}$ & $\begin{array}{c}\% \text { of ossified } \\
\text { enthesis }\end{array}$ \\
\hline \multirow[t]{4}{*}{ Femur } & 152 & Capsular ligament of hip joint & Intertrochanteric line & 5 & 3.28 \\
\hline & & Capsular ligament of knee joint & Articular margin of condyles & 8 & 5.2 \\
\hline & & Insertion of gluteus maximus & Gluteal tuberosity & 2 & 1.3 \\
\hline & & $\begin{array}{l}\text { Medial intermuscular septum \& } \\
\text { aponeurotic origin of vastus medialis }\end{array}$ & $\begin{array}{l}\text { Spiral line and medial lip of } \\
\text { linea aspera }\end{array}$ & 5 & 3.2 \\
\hline \multirow[t]{2}{*}{ Patella } & 72 & Quadriceps tendon & Base of patella & 7 & 12.5 \\
\hline & & Ligamentum patellae & Apex of patella & 2 & 2.7 \\
\hline \multirow[t]{3}{*}{ Tibia } & 77 & Ligamentum patellae & Tibial tuberosity & 26 & 33 \\
\hline & & $\begin{array}{l}\text { Insertion of tendon of sartorius, } \\
\text { gracilis \& semitendinosus. }\end{array}$ & $\begin{array}{l}\text { Upper end of medial surface } \\
\text { of tibia }\end{array}$ & 1 & 1.3 \\
\hline & & Tendinous origin of soleus & Soleal line & 4 & 5.4 \\
\hline Fibula & 58 & Posterior talofibular ligament & Malleolar fossa & 1 & 1.7 \\
\hline \multirow[t]{2}{*}{ Calcanium } & 87 & Tendoachillis & $\begin{array}{l}\text { Proximal surface of } \\
\text { calcaneum }\end{array}$ & 28 & 32 \\
\hline & & Plantar aponeurosis & $\begin{array}{l}\text { Medial process on the plantar } \\
\text { surface }\end{array}$ & 24 & 27.5 \\
\hline
\end{tabular}


Table 2: Ossification of enthesis in upper limb bones.

\begin{tabular}{|c|c|c|c|c|c|}
\hline $\begin{array}{c}\text { Name of the } \\
\text { bone }\end{array}$ & $\begin{array}{l}\text { Total number of } \\
\text { bones studied }\end{array}$ & Observation of ossified enthesis & $\begin{array}{c}\text { Sites of attachment to } \\
\text { the bone }\end{array}$ & $\begin{array}{l}\text { No. of ossified } \\
\text { enthesis }\end{array}$ & $\begin{array}{c}\% \text { of ossified } \\
\text { enthesis }\end{array}$ \\
\hline Scapula & 100 & Transverse scapular ligament & Suprascapular notch & 6 & 6 \\
\hline Clavicle & 74 & Costoclavicular ligament & $\begin{array}{l}\text { Inferior surface of medial } \\
\text { end of clavicle }\end{array}$ & 10 & 13.5 \\
\hline \multirow[t]{5}{*}{ Humerus } & 100 & Capsular ligament of shoulder joint & Anatomical neck & 4 & 4 \\
\hline & & Capsular ligament of elbow joint & Articular margin & 1 & 1 \\
\hline & & Lateral intermuscular septum & $\begin{array}{l}\text { Lateral supracondylar } \\
\text { ridge }\end{array}$ & 1 & 1 \\
\hline & & Common extensor tendon & Lateral epicondyle & 1 & 1 \\
\hline & & Common flexor tendon & Medial epicondyle & 2 & 2 \\
\hline \multirow[t]{2}{*}{ Radius } & 90 & Interosseous membrane & Interosseous border & 10 & 11 \\
\hline & & Insertion of tendon of biceps & Radial tuberosity & 3 & 3.33 \\
\hline Ulna & 80 & Insertion of Triceps & Olecranon process & 5 & 6.25 \\
\hline
\end{tabular}

\section{DISCUSSION}

It is well known that plane radiography, ultrasound and MRI demonstrate soft tissue thickening, bone erosion, new bone proliferation, and bone structure alterations at inflamed entheses. But this osteological study focused only on the sites and frequency of bony proliferation at entheseal sites in the appendicular skeleton.

Mechanical factors, physiological and anatomical characteristics of the enthesis, play an important role in the localization of enthesitis. In the course of normal joint function, strain levels at insertion sites maybe 4 times those in the tendon midsubstance [11]. So microtrauma and degenerative changes mostly affect the enthesis which is the principle of enthesitis development in spondyloarthropathy. This also explains the finding that most of the clinically relevant enthesitis sites are present in the lower limbs, particularly at the heel (Achilles enthesitis and Planter fasciitis).

Peggy Jacques et al have proved that enthesitis and new bone formation are driven by mechanical strain [12].

According to their study on animal model, the entheses are subjected to repetitive biomechanical stressing forces that are applied during normal muscle, ligament, and tendon action. In SpA patients, new bone formation often occurs in close relationship with the entheses. Development of spinal syndesmophytes along the anterior intervertebral ligaments, and bony spurs at the achilles tendon and plantar fascia are the results of this process. Subsequent bone erosion after inflammation appeared in anatomically distinct sites as compared with new bone formation at the achilles'enthesis. Erosions preferentially developed in regions undergoing compression, whereas spur formation occurred in regions prone to tensile forces. Baraka et al [13] in their study on ultrasonographic evaluation of lower limb enthesopathy in ankylosing spondylitis and Behçet's disease have reported that achillis tendon was most commonly affected followed by plantar aponeurosis. In both studied groups, the most commonly affected entheseal site was the achilles tendon insertion which was found to be affected in (30.5\%) sites in group I and (41.5\%) in group II, followed by the plantar aponeurosis attachment which was found to be affected in (27.78\%) sites of group I and 23/65 (35.38\%) in group II where the group I \& II represent cases of ankylosing spondylitis and Behcet's disease respectively. Our osteological study is consistent with the findings of this study with $32 \%$ in achillis tendon and $27.5 \%$ in plantar aponeurosis involvement.

Tibial tuberosity enthesophyte was the least frequent to be detected in their study. According to them several anatomical factors such as bone widening and sharp changes in the fiber orientation can lead to an anisotropic misleading artifact.But in the present study, tibial tuberosity enthesophyte was found in $33 \%$ cases which were higher as compared to other sites.

PV Balint et al [14] in an Ultrasonographic study of lower limb enthesis in SpA patients have reported that enthesophyte formation(3-30\%) was the most common USG bonyabnormality of 
entheseal sites while bony erosion was seen at $1-13 \%$ of sites. They observed ossification of entheses in 8/70 quadriceps, 7/69 proximal patellar ligament, 2/69 distal patellar ligament, 21/70 achillis tendon, 4/70 plantar aponeurosis. In contrast, our study showed more number of enthesophytes formation of the distal patellar ligament (26/77) and plantar aponeurosis(24/87).

Antonio Spadaro et al [15]in an imaging study of peripheral enthesitis in ankylosing spondylitis have reported that the distal portion of the lower limbs is more frequently affected by enthesopathic abnormalities compared with the proximal part of the lower limb. Similar results were reported by Lenthinen et al [16], Kiris et al.[17] and Wes Cormic [18]. All the above studies show that patellar tendon, achillis tendon, and plantar fascia are more commonly affected compared to the attachment of adductor muscles or gluteal muscles, which is consistent with our result.The reasons for the predilection of the distal part of lower limbs by the enthusiastic process is unknown, but anatomic and physiological factors, such as the major length of the tendon, may play a role $[15,19]$.

In the present study, we observed significant osteophytic changes along the medial lip of linea aspera in the femur and soleal line of the tibia which are the site of attachments of vastus medialis and soleus respectively. As described earlier, these types of entheses come under a different category called fibrous entheses which are usually associated with massive muscle bodies that attach directly to large areas of the diaphyses or metaphyses of long bones and dissipate stress from tendons over bone tissue [1]. We did not find a report on enthesopathy in these areas in any other literature.

Compared to lower limb enthesopathy less number of studies and reports are found on upper limb enthesopathy. Wes Cormic has mentioned about supraspinatus tendon enthesopathy, lateral epicondylar enthesopathy [18]. Resnick et al. [19] showed that the majority of the patients with DISH also showed clinical and radiographic abnormalities at locations other than the classical osteoarthritic sites including elbows, wrists, and shoulders. Littlejohn JO et al [20] have reported about hyperostosis on olecranon though the tibial spine, heel, patella were mainly involved.

Enthesopathy had an increased predictive value in diagnosing DISH [21,22]. Common sites of hyperostotic spurs were at the olecranon, lateral and medial epicondyle. The formation of these spurs is influenced by mechanical factors like physical activities, handedness, and sex. [ 23]. In the present study also hyperostotic spurs were mostly present around the elbow. Common flexor tendon, common extensor tendon, tendon of biceps, tendon of triceps, and capsular ligament of elbow joint were ossified at their attachment sites.

Though we found bony spurs in olecranon (6.25\%), lateral( $1 \%$ ) and medial(2\%) epicondyles they were less frequent as compared to costoclavicular ligaments(13.5\%), interosseous membrane (11\%) and suprascapular ligaments (6\%). Interestingly enthesophytic changes in the above structures have not been reported by earlier authors.

\section{CONCLUSION}

The bones we studied are from the general population, whereas other studies are in clinical cases. Still, we observed almost a similar result to other studies with little differences. Some entheseal sites of ossifications, which were not observed in imaging studies could be detected by gross examination of bones. This study can guide the clinicians and radiologists to focus on these sites to correlate with their findings.

\section{Conflicts of Interests: None}

\section{REFERENCES}

[1]. Schlecht SH Understanding entheses: bridging the gap between clinical and anthropological perspectives. Anat Rec (Hoboken) 2012;295:1239-1251.

[2]. Benjamin M, Toumi H, Ralphs JR, Bydder G, Best TM, Milz $\mathrm{S}$. Where tendons and ligamentsmeet bone: attachment sites ('entheses') in relation to exercise and/or mechanical load. J. Anat. 2006;208:471-490.

[3]. McGonagle D, Stockwin L, Isaacs J et al. An enthesitis based model for the pathogenesis of spondyloarthropathy additive effects of microbial adjuvant and biomechanical factors at disease sites. J Rheumatol 2001;28:2155-9.

[4]. Ward MM, Reveille JD, Learch TJ, et al. Occupational physical activities and long-term functional and radiographic outcomes in patients with ankylosing spondylitis. Arthritis Rheum 2008;59:822-32. 
[5]. Woo SL-Y, Maynard J, Butler D, Lyon R, Torzelli P, Akenson $W$, et al. Ligament, tendon, and joint capsule insertions to bone. In: Woo SL-Y, Buckwalter BJ, editors. Injury and repair of themusculoskeletal soft tissues. Park Ridge (IL): American Academy of Orthopaedic Surgeons; 1988;133-66.

[6]. Extraspinal manifestations of diffuse idiopathic skeletal hyperostosis Reuven Mader, Piercarlo SarziPuttini, Fabiola Atzeni, Ignazio Olivieri, Nicola Pappone, Jorrit-Jan Verlaan and Dan Buskila. Rheumatology 2009;48:1478-1481.

[7]. Cruickshank B. Pathology of ankylosing spondylitis. Clin Orthop1971;74:43-58.

[8]. Ball J. Enthesopathy of rheumatoid and ankylosing spondylitis. Ann Rheum Dis 1971;30:213-23.

[9]. Mader R, Verlaan J-J, Eshed I, et al. Diffuse idiopathic skeletal hyperostosis (DISH): where we are now and where to go next. RMD Open 2017;3:e000472.

[10]. McGonagle D, Khan MA, Marzo-Ortega H, O'Connor P, Gibbon W, Emery P. Enthesitis in spondyloarthropathy. Curr Opin Rheumatol 1999;11:244-50.

[11]. Olivieri I, Barozzi L, Padula A. Enthesiopathy: clinical manifestations, imaging, and treatment. Baillieres Clin Rheumatol 1998;12:665.

[12]. Jacques $P$, Lambrecht $S$, Verheugen $E$, et al Proof of concept: enthesitis and new boneformation in spondyloarthritis are driven by mechanical strain and stromal cells. Ann Rheum Dis. 2014;73:437445.

[13].E. A. Baraka, W. A. Hassan Musculoskeletal ultrasonographic evaluation of lower limbenthesopathy in ankylosing spondylitis and Behçet's disease: Relation to clinical status and disease activity. Egyptian Rheumatology \& Rehabilitation 2016;43:108-116.

[14]. P V Balint, D Kane, H Wilson, I B Mclnnes, R D Sturrock. Ultrasonography of entheseal insertions in the lower limb in spondyloarthropathy. Ann Rheum Dis 2002;61:905-910.
[15]. Antonio Spadaro, Fabio Massimo Perrota, Alessia Carboni \&Antonglulio ScarnoClinical and imaging assessment of peripheral enthesitis in ankylosing spondylitis. Int. J. Clin. Rheumatol. 2012:7(4).

[16]. Lehtinen A, Taavitsainen M, Leirisalo-Repo M. Sonographic analysis of enthesopathy in the lower extremities of patients with spondylarthropathy. Clin. Exp. Rheumatol. 1994;12:143-148.

[17]. Kiris A, Kaya A, Ozgocmen S, Kocakoc E. Assessment of enthesitis in ankylosing spondylitis by power Doppler ultrasonography. Skeletal Radiol. 2006;35:522-528.

[18]. Wes Cormick Enthesopathy - a personal perspective on its manifestations, implications, and treatment AJUM November 2010;13(4):19-23.

[19]. Resnick D, Shaul SR, Robins JM. Diffuse idiopathic skeletal hyperostosis (DISH): Forestier's disease with extraspinal manifestations. Radiology 1975;115:513-24.

[20]. Littlejohn JO, Urowitz MB. Peripheral enthesopathy in diffuse idiopathic skeletal hyperostosis (DISH): a radiologic study. J Rheumatol 1982;9:568-72.

[21]. Haller J, Resnick D, Miller CW, et al. Diffuse idiopathic skeletal hyperostosis: diagnostic significance of radiographic abnormalities of the pelvis. Radiology1989;172:835-9.

[22]. Slonimsky E, Leibushor N, Aharoni D, et al. Pelvic enthesopathy on CT is significantly more prevalent in patients with diffuse idiopathic skeletal hyperostosis (DISH) compared with matched control patients. Clin Rheumatol 2016;35:1823-7.

[23]. Beyeler C, Thomann SR, Gerber NJ, et al. Diffuse idiopathic skeletal hyperostosis (DISH) of the elbow: a controlled radiological study. BMC Musculoskelet Disord 2015;16:119.

How to cite this article:

S. Behera, S. Singh, M. Sar. PERIPHERAL ENTHESOPATHY: AN OSTEOLOGICAL STUDY. Int J Anat Res 2020;8(3.2):7633-7637. DOI: $10.16965 /$ ijar.2020.178 